\title{
Por um currículo sem fundamentos ${ }^{1}$
}

\author{
Alice Casimiro Lopes \\ Universidade do Estado do Rio de Janeiro
}

\section{Resumo}

Por intermédio de um enfoque pós-estrutural e pós-fundacional, este artigo apresenta uma argumentação crítica ao projeto de base curricular nacional comum. Para tal, investiga alguns textos sobre base curricular nacional, com destaque para os programas de governo dos presidenciáveis de 2014, no Brasil: Aécio Neves, Dilma Roussef e Marina da Silva (substituindo Eduardo Campos). A política por um currículo sem fundamentos significa defender que não há princípios e regras curriculares absolutos, definidos cientificamente ou por qualquer outra razão, fora do jogo político educacional.

Palavras-chave: Base curricular nacional comum. Política de currículo. Discurso. Contextualização. Padrões curriculares. 


\section{For a Curriculum without Fundamentals}

Through a post-structural and a post-foundational approach, this paper argues critically against the proposal for a national curriculum common core. For this purpose, a few texts on national curricular bases were investigated, especially the government programs of the 2014 presidential candidates in Brazil: Aécio Neves, Dilma Roussef and Marina da Silva (replacing Eduardo Campos). The policy for a curriculum without fundamentals means defending that there are no absolute curricular principles and rules, defined scientifically or on any other basis, which are not part of the political game in education.

Keywords: Contextualization. Curriculum policy. Discourse. National curriculum common core. standards.

\section{Por un Currículo sin Fundamentos}

De acuerdo con un enfoque posestructural y posfundacional, este artículo argumenta en contra de la propuesta de currículo común nacional. Para eso, son investigados algunos de los textos sobre la base curricular nacional, especialmente los programas de gobierno de los candidatos presidenciales en Brasil, en 2014: Aécio Neves, Dilma Roussef y Marina da Silva (en sustitución de Eduardo Campos). Una política por un currículo sin fundamentos significa defender que no hay principios y reglas curriculares absolutas, definidas científicamente o por cualquier otra razón, fuera del juego político educativo.

Palabras-clave: Contextualización. Política de currículo. Discurso. Currículo común nacional. Estándares curriculares. 


\section{Introdução}

Neste texto, parto do entendimento da política de currículo como uma luta pela significação do que vem a ser currículo. Com esse entendimento, busco me afastar de enfoques racionalistas - liberais ou não -, apostando no descentramento da política, na contextualização radical de toda política de currículo. Mobilizada por essa interpretação, tenciono questionar propostas atuais que visam a construir um fundamento, um padrão, uma base curricular, um conjunto de conteúdos básicos ou mesmo um conjunto de critérios consensuais para definir de uma vez por todas uma identidade para o currículo da educação básica.

Tais propostas frequentemente são supostas como nacionais a partir da estabilização do conceito de nação não apenas como território físico, mas como espaço simbólico, cultural. Não me dedico neste texto à discussão sobre a ideia de nacional - aos interessados na desconstrução do conceito de nação, sugiro ver Bhabha (2001). Focalizo mais detidamente a pretensão de se instituir algo que se entenda como comum.

Nessa discussão, vale a tentativa de esclarecer um pouco mais tanto a ideia de descentramento quanto a ideia de contexto. Descentrar não é multiplicar os centros de poder e significação, de maneira a estabelecer alternativas ocasionais entre um centro e outro. Também não é manter um centro único, porém provisório no tempo. É conceber que todo centro é instável e fugidio; sujeito à disputa, no tempo e no espaço. De forma correlacionada, os contextos não são espaços dados, com fronteiras definidas, existentes no mundo, mas construções discursivas no/ do mundo. A produção de centros e contextos da política (de currículo) depende de atos de poder, constitui - e é constituída por - certos discursos (pedagógicos).

Neste texto não desenvolvo mais detidamente as discussões teóricas que tenho empreendido, ainda que elas estejam sempre balizando o que penso, o que escrevo, o que falo. Desenvolvi alguns desses pontos em outros trabalhos (Lopes, 2012a, 2012b, 2014; Lopes \& Macedo, 2011). Meu foco é o de apresentar como se modifica a compreensão da política de currículo por intermédio de minhas investigações e apresentar também outras possibilidades abertas por essa compreensão no que concerne às diretrizes/orientações/bases curriculares nacionais - foco de debate neste momento. Em outros termos, quero apresentar algumas das conclusões que as discussões teóricas construídas pelo grupo de pesquisa ${ }^{2}$ que coordeno têm gerado no sentido de conceber de forma diferente as políticas de currículo.

Estou comprometida com a interpretação da política realizada no âmbito dos enfoques pós-fundacionais e pós-estruturais (Lopes, 2013). Com essa 
interpretação, o propósito utópico fixo de mudança social - a sociedade sem poder ou sem classes, a sociedade sem desigualdades, sem conflitos, ou qualquer outra construção utópica análoga que se possa enunciar - é abandonado ou pelo menos substituído por agendas contextuais e localizadas, impossíveis de serem enumeradas. Tal impossibilidade não se deve a uma multiplicidade empírica, um grande número de contextos diferentes que como tais existem, porém são impossíveis de serem enumerados dada a nossa incapacidade teórica e empírica para tal. A impossibilidade de enunciar - e enumerar tais contextos - é radicada no fato de que tais agendas contextuais se constituem e se modificam no próprio movimento da política. Os contextos, em outros termos, não são objetos preexistentes à espera da ampliação de nossa capacidade de indicarmos suas fronteiras e assim identificá-los.

Nesse processo, igualmente é questionado o estabelecimento de princípios absolutos, mesmos os genéricos, para guiar a atuação política. A política é da ordem do acontecimento, remete a uma ética que não pode ser definida a priori e de uma vez por todas. Sem definições que nos guiem, sem metas que prescrevem (pré-escrevem, pré-inscrevem) um caminho, só nos cabe o comprometimento e a responsabilidade. Não a responsabilidade da métrica de performances predefinidas por um suposto contexto social consensuado. Mas aquela que se deriva do comprometimento, do ato de responder, da aposta no que se pretende realizar.

A política deixa de ser uma determinação - em primeira ou em última instância - da economia para assumir primazia na constituição do social. A economia é ela mesma política, depende de decisões políticas. Os discursos instituídos da política - linguagem, práticas, instituições - são entendidos como formas de ordenar dimensões, mas também como capazes de subverter e refundar o social de outras maneiras, reconhecidamente antagônicas e conflituosas. Política remete muito mais a conflito do que a consenso, muito mais a produção de sentidos e movimentos diferentes do que a definição de universalismos categóricos e de regras de organização.

Há múltiplas demandas contextuais, mais que isso, contingentes (Laclau, 1990), produzindo sentidos para as políticas. Por isso mesmo as políticas têm sua perspectiva racional e estruturada fortemente questionada e passam a ser admitidas como incoerentes, contraditórias, não coesas, desordenadas. É característico da política assim ser. Isso não é uma incapacidade de se fazer política, uma incompetência dos políticos lou dos seres humanos) ou uma deturpação de uma regra política. A política é construída por articulações de demandas. Há equivalências entre demandas frente a um exterior representado como ameaça ao atendimento dessas mesmas demandas. Tais demandas são 
diferenças que podem ser estancadas, mas não tornadas iguais. 0 movimento que reduz a diferença por intermédio da equivalência não bloqueia o livre fluxo do diferir associado às dinâmicas contextuais. Nem a equivalência resvala para uma igualdade, nem a diferença é completamente bloqueada.

No caso particular das políticas de currículo, é possível afirmar que são decorrentes de diferentes articulações entre demandas representadas como advindas de comunidades disciplinares, equipes técnicas de governo, empresariado, partidos políticos, associações, instituições e grupos/movimentos sociais os mais diversos. Por intermédio das articulações entre essas demandas diferenciais, grupos políticos são organizados, significações de currículo são instituídas. Um dos possíveis exemplos dessas lutas é a que se organiza em torno dos sentidos de qualidade da educação. (Matheus \& Lopes, 2014)

Aqui vale destacar que essa perspectiva teórica também pode ser denominada discursiva ${ }^{3}$. Nesse enfoque, discurso não é só linguagem, aquilo que se fala ou se escreve. Discurso é prática. É linguagem e ação; uma prática de significação. Não significa uma opção por "negar a realidade", como críticas embasadas no realismo tendem a afirmar. Significa defender que toda realidade é compreendida discursivamente: o próprio ato de nomear algo como realidade envolve um discurso que sustenta esta nomeação. Considerar, por exemplo, o objeto floresta amazônica como o pulmão do mundo ou o empecilho ao desenvolvimento regional ou mera fonte de madeira a ser convertida em dinheiro depende de articulações discursivas que produzem tal significação e com isso também produzem práticas e efeitos sociais, produzem sujeitos e contextos políticos: o defensor e a defesa do meio ambiente; o político desenvolvimentista e a concepção desenvolvimentista; a extração de madeira e o explorador do extrativismo da madeira, dentre outros. Tais significados não são dependentes de alguma essência objetiva. Se o currículo é entendido como planejamento, lista de conteúdos, saberes legitimados ou luta pela significação da cultura, isso também depende de articulações discursivas, não de uma propriedade intrínseca a um objeto - o currículo - considerado como um dado inequívoco. Apostar em um enfoque discursivo que constitui a realidade tal como a compreendemos significa também estar constantemente negociando com uma série de tradições, de registros estruturados com e pelos quais somos/ fomos formados, admitir os deslizamentos em outras direções, recriando esses

3. Aos interessados em conhecer uma breve genealogia de diferentes entendimentos de discurso, dos mais realistas aos antirrealistas, passando pelos que se autodenominam realismo crítico; dos primeiros estudos de Saussure aos trabalhos de Derrida e Laclau, passando por Bakhthin, Fairclough e Foucault, recomendo Howarth (2000). Proponho, todavia, que a síntese de Howarth não seja vista como uma evolução linear do conceito/operador discurso, mas como diferentes abordagens teóricas com problemáticas distintas, que se confrontam e se diferenciam. Apoio-me aqui no enfoque antirrealista, que não pretende dar conta do Real, no sentido lacaniano, inspirado em Derrida e Laclau. 
mesmos registros. É conceber que o poder está implicado em todas as dimensões de conhecimento e de razão.

Tais registros são incorporados à educação levando a que sejam repensadas suas finalidades sociais, pois tais finalidades, caso sejam compreendidas discursivamente, deixam de ter um fundamento racional, calculado, capaz de sustentar uma dada escolha. Com isso, a opção por dada finalidade social, a enunciação dessa finalidade e sua defesa, são inseridas na esfera da política. São definidas em certas relações de poder.

Meu propósito é tentar operar por referência à desconstrução de discursos, nos termos de Derrida $(2005,2008)$, e à sua reativação, nos termos de Laclau (1990). Desconstrução para Derrida não é um método ou uma operação a ser aplicada deliberadamente por um sujeito consciente sobre um texto ou um discurso. Todo texto está impregnado por um princípio desconstrutor, a desconstrução faz parte da lógica do texto (Derrida, 2005; Siscar, 2013). Operar com a desconstrução é se dispor ao acontecimento, admitir a tradução que se faz de qualquer texto, o diferir de qualquer leitura. Laclau (1990), por sua vez, inspirado na desconstrução, se apropria dos conceitos de sedimentação e reativação de Husserl traduzindoos no seu corpo teórico sobre o antagonismo na política. Reativar discursos é simultaneamente abalar o que se encontra sedimentado, estabelecido como objetivo, como fundamento, como presença plena, e fazer emergir os antagonismos, o caráter indecidível e contingente das alternativas. 0 que se encontra sedimentado é sempre decorrente da decisão por uma alternativa, decorrente de um ato de poder e não de uma suposta racionalidade obrigatória. E a escolha por certa opção será sempre a exclusão de outras tantas opções negadas, algumas vezes sequer passíveis de serem enunciadas.

Há fundamentos estabilizados, discursos que sustentam formas de compreender o currículo e a política de currículo. Procuro entender o que sustenta e constitui esses fundamentos, tento abalar o que se encontra sedimentado, tento problematizar a norma que parece guiar as políticas de currículo, acreditando ser importante apresentar outras possibilidades para pensar/operar essa mesma política. Nesse enfoque, defendo o que venho denominando currículo sem fundamento, sem bases, sem um chão capaz de frear a significação do currículo. Coloco-me assim no interior da disputa política pela significação do currículo e entendo que meus textos, e tantos outros textos, são também tentativas de produzir sentidos na política de currículo.

A meu ver, essa é a importância do trabalho teórico. Tentar apresentar outra forma de compreender para além do que já se encontra estabilizado. É como estar sempre se perguntando: mas não poderia ser de outro modo? 0 que está possibilitando e sustentando a significação com a qual operamos e que nos subjetiva 
(nos faz ser ou ser identificado como sendo) de uma determinada maneira? Por que pensar desse modo que é apresentado como única possibilidade, como caminho universalizado e naturalizado, sem que sejam discutidas as condições contextuais que possibilitaram tal proposta? Não se trata de assumir uma posição como certa ou errada criando um novo fundamento, mas tentar entender o que uma dada perspectiva viabiliza e o que bloqueia. Não é uma questão de deve ou não deve, pode ou não pode. Remete à problematização, provocar outras possibilidades de pensar, conceber outras maneiras de objetivar, desestabilizar discursos, sabendo que isso implica estabilizar outros discursos e, portanto, cabe manter aberta a suspeição diante de toda estabilidade.

\section{Desestabilizando discursos}

Trago para o debate registros sobre currículo com a intenção de discutir como eles operam na sustentação de algumas das atuais representações do que vêm a ser currículo e política de currículo. Reporto-me primeiramente à história recente sobre a definição de propostas que pretendem nortear as políticas curriculares. Durante o mandato presidencial de Fernando Henrique Cardoso, foram publicados, e fortemente difundidos, as diretrizes e os parâmetros curriculares nacionais, com base na LDB de 1996: as diretrizes curriculares nacionais para 0 ensino fundamental em 1998, o parecer dos parâmetros curriculares nacionais para o ensino fundamental, em 1997; os parâmetros e as diretrizes curriculares nacionais para o ensino médio, em 1998. Esses documentos foram apoiados por vários setores sociais, inclusive no campo educacional, mas também foram extremamente questionados, principalmente por curriculistas. Frequentemente foi afirmado o caráter neoliberal dessa iniciativa, vinculando-a tanto à ideia de construção de um currículo comum nacional a ser avaliado de forma centralizada quanto à submissão a orientações internacionais. Os textos de Antonio Flavio Moreira e Tomaz Tadeu da Silva no fim dos anos 1990 são emblemáticos desses enfoques.

Durante os mandatos de Luís Inácio Lula da Silva e Dilma Roussef, houve a divulgação das orientações curriculares nacionais, em 2006. São mais gerais e recentes os documentos dirigidos à educação básica e ao ensino médio (Brasil, Parecer e Resolução CNE 2010, Parecer CNE 2011, Resolução CNE 2012). Tais textos mantêm a lógica de constituição de um currículo nacional, mas foram recebidos com críticas mais matizadas e bem mais discretas do que aquelas que foram dirigidas aos parâmetros curriculares. Não apenas por certo apoio da academia ao Partido dos Trabalhadores, mas também porque a própria teorização 
sobre as políticas de currículo passou a produzir análises menos deterministas e mais complexas. Por sua vez, em função dessas muitas propostas curriculares produzidas com o apoio do MEC, vários Estados e Municípios organizaram projetos curriculares próprios que vêm sendo compreendidos como recontextualizações, traduções, híbridos políticos ou releituras contextuais das propostas nacionais. (Barreto \& Lopes, 2010; Cunha \& Lopes, 2013; Frangella \& Barreiros, 2007; Lima e Lopes, 2011; Matheus \& Lopes, 2011, 2014; Oliveira, 2008; Tura \& Pereira, 2013)

Passados quase vinte anos, a ideia de um currículo comum e seu vínculo necessário com a organização de um sistema educativo de qualidade parece ter se hegemonizado, mesmo que os atuais textos orientadores não sejam difundidos de forma tão avassaladora como foram (ou nos pareceram ser) os primeiros parâmetros curriculares nacionais publicados durante o mandato de Fernando Henrique Cardoso. 0 movimento por uma base nacional comum da educação tem ganhado cada vez mais adeptos e já se constitui como uma rede que se apresenta como ampla e sem direção (cf. http://basenacionalcomum.org.br/). Uma rápida busca no Google também permite intuir o alcance da mobilização em torno dessa base. Igualmente foi iniciada a elaboração, dirigida pelo MEC, de uma proposta que pretende produzir um currículo para as escolas do País, por meio de uma base curricular unificada. (Roxo, 2012; Massali, 2014)

Por sua vez, recentemente, foi divulgado amplamente o plano de governo dos então três principais candidatos à presidência nas eleições de 2014 - Aécio Neves (PSDB), Dilma Rousseff (PT) e Eduardo Campos (PSB) (Weber, 2014). Os três afirmaram a necessidade de realizar mudanças no currículo das escolas brasileiras. Os três prometeram melhorar a qualidade do ensino e, para isso, defenderam a definição de uma base comum nacional, para além do que já está definido nas diretrizes curriculares nacionais da educação básica. Segundo foi divulgado nesta matéria jornalística, “a ideia é estabelecer conteúdos mínimos que os alunos devam aprender ano a ano, no ensino fundamental e médio" (Weber, 2014), considerando que essa base é prevista na LDB, mas nunca saiu do papel.

Esta mesma proposta não é apresentada no programa de governo de Dilma Roussef, porém tampouco é desmentida, levando a crer que se buscará a continuidade com o processo em curso no governo atual. Muito provavelmente pretende-se que esta etapa esteja concluída antes do fim do mandato. (programa de governo da candidata Dilma Roussef, 2014)

0 plano de governo de Aécio Neves, por sua vez, é mais contundente quanto à afirmação desta proposta, sendo defendida a:

Definição de uma Base Nacional Comum para os currículos da educação básica dos sistemas de ensino estaduais e municipais, estabelecendo com clareza e objetividade o que 
é básico e indispensável que todos os alunos brasileiros aprendam em cada ano e etapa de escolaridade obrigatória. A ser definida com a participação de estados, municípios, entidades representativas da educação pública e privada e da sociedade civil em geral, a Base Nacional Comum, tal como apresentada no Artigo 26 da LDB, preservará a autonomia pedagógica e metodológica dos sistemas de ensino público e das escolas particulares e será referência para: a formação de professores; a produção de recursos didáticos e tecnológicos que venha a ser apoiada pelo poder público; a revisão e modernização das matrizes de referência da avaliação da educação básica, SAEB/Prova Brasil, de modo a estabelecer uma relação clara entre o que está sendo avaliado e o currículo ensinado nas escola. (plano de governo do candidato Aécio Neves, 2014, p. 49, grifos meus)

Na medida em que a proposta apresentada por um candidato à presidência não é pessoal, mas resultado de uma articulação mais ampla que, se não se mantém na ausência do líder (refiro-me ao falecimento de Eduardo Campos), também não se desfaz completamente, recorri ao programa de governo de Marina da Silva, sucessora de Eduardo Campos na disputa presidencial. Em seu programa de governo (programa de governo da candidata Marina da Silva, 2014), Marina da Silva, ainda que trouxesse maior ênfase na necessidade de adequar os currículos às diferenças regionais e à diversidade cultural e ambiental do País, defende igualmente a necessidade de:

Redesenhar e aprimorar a formação inicial e continuada dos profissionais da educação, alinhando-as com as estratégias para melhoria da Educação Básica no Brasil, com os conhecimentos e demandas do mundo contemporâneo e com uma base curricular nacional. (programa de governo da candidata Marina da Silva, 2014, p. 110)

Também defende “criar uma política de responsabilização por resultados da educação, aperfeiçoando os indicadores que compõem o Sistema Nacional de Avaliação da Aprendizagem da Educação Básica". (programa de governo da candidata Marina da Silva, 2014, p. 103)

Por um momento, não quero discutir aqui as diferenças entre essas propostas - e são muitas as diferenças, pois são distintas as articulações discursivas que as possibilitaram. Quero dar destaque, ao contrário, à unidade em relação à defesa de uma base curricular nacional comum, seu vínculo com a qualidade da educação e a solução de (grande) parte dos problemas educacionais, bem como aos esforços realizados para garantir essa base.

Começo salientando que não analiso as propostas curriculares nesses últimos 17 anos como resumidas aos registros neoliberais ou como submetidas aos ditames internacionais. Tais práticas e decisões são discursivas, portanto não são 
do governo, das agências multilaterais, deste ou daquele partido lainda que não sejam de qualquer um e haja um sentido em ser deste ou daquele partido, deste ou daquele governo, vinculada a este ou aquele nomel. Muitos do que leem ou lerão este texto não são vinculados a esses projetos de governo ou a esses partidos, mas ainda assim defendem uma base curricular comum nacional e vinculam essa base à melhoria de qualidade da educação. Conecto essa posição ao que já apresentei sobre a compreensão discursiva da política de currículo. A política não tem um centro de poder, uma estrutura que a defina. Articulações discursivas possibilitam decisões políticas, tornando complexo o jogo (de linguagem) que hegemoniza uma dada orientação curricular.

Apenas como contraponto do que estou argumentando, trago dois exemplos de reivindicações, com propósitos políticos muito distintos, que remetem à ideia de currículo nacional. 0 primeiro é a recomendação número 1 do relatório "Saindo da Inércia - boletim da educação no Brasil", publicado em 2009 pelo PREAL (Programa de Promoción de la Reforma Educativa en América Latina y el Caribe): criar e implementar padrões curriculares. Este relatório reforça a conclusão apresentada em um relatório do PREAL (1998) “El Futuro está en juego". Este relatório conclui quanto à necessidade de:"Establecer estándares nacionales de contenido y rendimiento, que reflejen lo que los alumnos deben saber al término de cada grado. Los estándares deben estar relacionados con las necesidades de la economía global y el sistema democrático". (PREAL, 1998, p. 15)

O segundo é a conclusão de um estudo sobre as demandas da Revolução Pinguina (Leal Cuevas, 2014), movimento político que começou no Chile a partir dos estudantes secundaristas e que, por meio de várias articulações políticas contra toda política significada como neoliberal, se ampliou ganhando inclusive destaque internacional. Também esse movimento, que se constitui como antineoliberal e atua contra as políticas que consideram terem tornado a educação chilena um grande negócio, em seus momentos iniciais incorporou reivindicações educativas vinculadas à defesa de um currículo comum nacional capaz de garantir a qualidade da educação, bons resultados nos exames nacionais, formação para o emprego e inserção no mundo globalizado.

Não estou com isso desresponsabilizando governos, ou desconsiderando as diferentes relações de poder que constituem tais discursos ou mesmo afirmando que se trata exatamente do mesmo sentido em diferentes contextos. Considerando a perspectiva de uma contextualização radical, a significado de uma luta política deve levar em conta as contingências que possibilitam essa significação. Não é possível fazer referência a um sentido universal de currículo de qualidade, a uma verdade sobre o que vem a ser o melhor currículo em qualquer contexto.

Por isso mesmo, ao contrário, amplio o processo de cada um se responsabilizar, 
tentando entender os modos como são construídas essas subjetivações/ identificações a ponto de não ser questionado esse vínculo tão imediato entre padrões curriculares e melhoria de qualidade da educação. Por militar academicamente no campo do currículo, preocupa-me como essa conexão encontra respaldo em nossos discursos pedagógicos, em nossas bandeiras de luta, e hoje se desenvolve em torno da necessidade de se constituir uma base curricular nacional.

A história do currículo é marcada pela ideia de que possa existir uma base racional que sustente as decisões sobre os saberes e atividades de ensino, seja ela em função de princípios epistemológicas, psicológicos, ou mesmo emancipatórios. Os focos nos objetivos, na transformação social, nos saberes universais são exemplos desses processos. As finalidades sociais se modificam - formar 0 profissional adequado ao mercado trabalho, formar o sujeito crítico, formar o sujeito emancipado, o cidadão -, mas as tentativas de conter a significação se mantêm. Tais processos de contenção do diferir são legítimos, não há política ou comunicação sem balizamentos a deter provisoriamente e de forma precária o livre fluxo de sentido. Todavia, mostra-se questionável, a meu ver, a tentativa de ver tais processos de contenção como sustentados por princípios externos à própria luta política. Faz parte da política a defesa desta ou daquela proposta curricular, apresentar projetos em nome de distintos objetivos. Parece-me questionável, contudo, considerar que tais projetos e propostas podem ser definidos por alguma teoria pedagógica, algum princípio racional, algum cálculo preestabelecido, algum fundamento apresentado como imune à necessidade de negociar contextualmente e de ser submetido à tradução pelos tantos outros que constituirão tais projetos e propostas. Torna-se questionável submeter tais projetos à pretensão de medir, comparar e avaliar conhecimentos/padrões de aprendizagem para alcançar a medida/comparação/avaliação de pessoas.

Na revisão de Camilloni (2009), pode-se conhecer um breve histórico desses padrões, bem como de seus vínculos com a avaliação centrada nos resultados e com a busca de padrões que garantam aos empregadores competências e aprendizagens dos cidadãos escolarizados. Parece-me necessário confrontar a pretensão de organizar um debate nacional para discutir a construção de uma base comum nacional, uma vez que os termos desse debate já são vinculados a uma série de pressupostos que não são postos em questão: vínculo imediato entre educação e desenvolvimento econômico, caráter salvacionista da educação (quase todos os problemas sociais são supostos como resolvidos com mais educação), redução da educação a níveis de aprendizagem e ao fornecimento de garantias sociais de que todos os alunos terão credenciais/padrões de aprendizado uniformes, restrição da crítica teórica à base comum nacional ao registro ideológico - sob certo registro 
depreciativo da ideologia, como em PREAL (2009) -, suposição de que professores não sabem o que fazer nas escolas sem uma base nacional predefinida.

Preocupa-me, em contrapartida, discursos do campo educacional apostarem tão facilmente na ideia de uma base curricular comum, apoiados na proposta de distribuir conhecimentos iguais para todos, como se conhecimento fosse um objeto, um dado, uma coisa, a ser captado, registrado e depois distribuído. Preocupa-me como se desconsidera a dimensão do currículo como negociação que produz discursivamente conhecimento na escola em conexão com tantas outras produções socialmente instituídas. Como se qualquer base curricular, qualquer proposta, qualquer padrão, qualquer texto, não estivesse submetido à tradução, a uma contextualização radical. Como se qualquer texto não estivesse submetido a ser outra coisa, uma vez que é disseminado e lido. Preocupa-me como o debate teórico pedagógico é desconsiderado.

Uma proposta curricular não é nacional ou comum, no sentido de saturar com os mesmos sentidos toda e qualquer significação nos mais diferentes contextos em foco, a ponto de ser transparente em relação aos sentidos que transmite. Como discute Siscar (2013), com base em Derrida, qualquer texto morre se não for lido, precisa fracassar na sua textualidade - a de transmitir uma orientação, uma visão, uma fixação de sentido - para existir. Mas também nunca fracassa completamente, senão deixaria de ser um texto (ter um efeito de sentido).

Na medida em que se opta por atuar de forma centralizada na política de currículo, há uma redução das políticas à tentativa de controlar as leituras das bases/padrões/ propostas curriculares visando alcançar (supostamente) a qualidade da educação. A política de currículo passa a ser uma estratégia calculada para determinado fim preestabelecido. São escritos parâmetros, diretrizes, orientações, propostas que vão sendo cada vez mais detalhados, tentando tornar mais explícitos os conteúdos a serem formados e as atividades escolares a serem realizadas (talvez um dos exemplos mais emblemáticos dessa tentativa tenham sido os PCNs em ação e os PCNst, ainda no mandato de Fernando Henrique Cardosol. São instituídos os exames, a distribuição de livros didáticos, são estabelecidos controles dos projetos Estaduais, Municipais e escolares, todo um esforço é dirigido à tentativa de controlar o que não pode ser controlado, a tentar garantir o que se supõe como leitura certa e que nunca será lida como tal. Tais propostas tentam tornar igual o que obrigatoriamente, pelo complexo processo discursivo, será sempre diferente.

Pode ser contra-argumentado que, se a leitura sempre pode ser outra, se o significante reiterado está sujeito aos jogos de linguagem do diferir, capazes de introduzir outros sentidos, produzir outra significação, não é um problema que se defina uma proposta curricular como base comum nacional. Tal base nunca produzirá homogeneidade, nunca será a plena colonização das escolas, sempre 
haverá formas de escape e de outras leituras.

Do meu ponto de vista, não haverá esse currículo plenamente produzido numa dada direção, seja ela qual for. Sempre diferentes discursos - mercado, emancipação, cidadania, mundo em mudança, qualidade de ensino, adequação à globalização, saberes universais, conteúdos básicos, justiça social, igualdade, diferença - estarão disputando a significação do que vem a ser currículo e produzindo significações imprevistas.

Trago aqui para o debate a necessidade de discutir no que resulta todo esse esforço para constituir uma base curricular comum nacional que nunca será instituída de fato. Seria possível falar dos enormes investimentos financeiros, subsidiados por acordos internacionais e nacionais, dirigidos para viabilizar essa tentativa, que poderiam ser investidos em outras ações curriculares descentradas. Tal ponto me parece importante de ser questionado, mas não é a isto que quero dar destaque aqui. Quero salientar como a proposta de unificar um projeto curricular comum pressupõe fundamentos que não contribuem para projetos que possibilitem ampliar sentidos democráticos.

\section{Fundamentos que não ampliam sentidos democráticos}

Formular conteúdos curriculares comuns, a despeito do jogo político, pressupõe tratar todos os estudantes como iguais e, por isso, merecedores (ora necessitados, ora com direitos) dos mesmos saberes. Como fica, nessa perspectiva, a questão de que estamos sujeitos ao diferir que não pode ser homogeneizado? Estamos fadados à heterogeneidade que não permite afirmar, seja por merecimento, necessidade ou direito, quais saberes são/ serão passíveis de estar conectados a essas múltiplas singularidades. A heterogeneidade que menciono não é associada ao fato de o Brasil ser um país muito grande ou uma nação marcada pela diversidade, mas porque cada contexto implica a possibilidade de outra leitura, outro texto, outra possibilidade de ser. Os argumentos que aqui apresento podem ser aplicados a um país como o Uruguai ou Portugal tanto quanto a um país como o Brasil.

Uma base curricular nacional comum, tal como vem sendo defendida, pressupõe apostar em um registro estabelecido como tendo um selo oficial de verdade, um conjunto de conteúdos que adquire o poder de conhecimento essencial a ser ensinado e aprendido, esforços para conter a tradução e impor uma leitura como a correta. Pressupõe apostar no consenso curricular como se ele fosse possível fora da disputa política contextual. Pressupõe tentar produzir o futuro por meio da formação de um ideal de sujeito educado que não pode 
ser garantido. Pressupõe que seja possível estabilizar a tradução do currículo e estancar, em um momento prévio à ação política do currículo, o conflito que constitui os saberes. Por isso, o debate e a deliberação são sempre situados como anteriores à construção da base, como se uma vez que o consenso fosse estabelecido, a deliberação política cessasse.

Soma-se a isso que o discurso que aposta no conhecimento comum muitas vezes opera com uma obrigatória imagem homogeneizante e negativa de escola. A base curricular nacional comum, nesse sentido, é concebida para suprir o que falta à escola. E quanto mais se deseja afirmar o valor da base comum a ser construída, mais se significa a escola (e os professores que nela trabalham) como carentes de algo, mais se realiza uma homogeneização das escolas como lugares onde não se aprende. Mesmo porque a positividade do projeto apresentado é dependente do diagnóstico negativo das escolas. Nas palavras de Maria Helena Guimarães de Castro, ex-presidente do INEP e coordenadora do programa de educação do candidato à presidência Aécio Neves (PSDB): O Brasil está atrasado nesse debate. Hoje os alunos não aprendem os conhecimentos essenciais que precisam aprender a cada ano. Todos os países têm currículo nacional ou base curricular comum. (Guimarães apud Weber, 2014, grifos meusl

Não é problematizado o que se entende por conhecimentos essenciais e por que é possível afirmar tão taxativamente que os alunos não aprendem tais conhecimentos. A generalidade imprecisa do "todos" - todos os alunos, todos os países - mascara as diferenças entre contextos.

Por mais que também seja afirmado que a base comum nacional não interfere na autonomia dos Estados, Municípios e escolas e por mais que também tenha que ser considerado que, muitas vezes, secretários de educação dos Estados e Municípios e diretores de escolas clamam por essa definição centralizada para dar um norte e servir de apoio às suas ações, a base curricular comum contribui para frear projetos contextuais e se tornar referência única. Vale destacar que frear os projetos locais não significa impedi-los, impossibilitá-los, saturar a significação de uma vez por todas por intermédio da base comum nacional, uma vez que os processos de tradução permanecem atuando. Ainda assim, contribui para que traduções contextuais sejam consideradas complementos submetidos à norma, algo da ordem do não prioritário, acréscimo local, não referente ao conhecimento, este sim já contido na base. A base se transforma em referência para avaliações centralizadas, livros didáticos, editais federais, ações de formação inicial e continuada de professores. Faculta uma 
tendência a invisibilizar experiências que contextualmente produzem possibilidades conectadas a finalidades de justiça social, melhoria da vida das pessoas, outras possibilidades de ser no mundo. A reforma educacional é concebida como a mudança que pode/deve ser organizada sem considerar o obrigatório diálogo crítico com as experiências em curso nas escolas.

Apostar nas bases curriculares comuns tende a operar com uma noção de conhecimento como um objeto, algo a ser transmitido e não uma produção cultural sempre traduzida. O conhecimento torna-se um dado externo ao sujeito, destituído de vínculos com suas experiências, com o fluxo discursivo contextual, com dinâmicas que não se limitam aos registros disciplinares e/ou científicos, reduzido à métrica dos índices instrucionais (Lopes, 2012b; Macedo, 2012). Com isso, o conhecimento é suposto como passível de ser apropriado, medido, listado, aplicado. É adjetivado como comum ou diversificado, essencial (e universal) ou local, sem que esses adjetivos sejam postos sob suspeição crítica. E quanto mais se caminha na tentativa de uniformizar esse conhecimento e decidir qual a base comum, mais se precisa afirmar que não será homogêneo, que há espaço para o diferente, como se a diferença fosse outra lista de itens previamente conhecidos, a serem inseridos ou não no currículo.

Outro efeito associado à lógica de se operar com a construção de uma base curricular comum é a de aceitar, praticamente sem críticas, os resultados de exames internacionais, como, por exemplo, o PISA (Programme for International Student Assessment), naturalizando o próprio exame. 0 propósito de construir um currículo comum é articulado à ideia de que o conhecimento é neutro e pode ser reduzido a um conjunto de índices passíveis de serem medidos em uma prova internacional lalém das muitas provas nacionais, igualmente naturalizadas). Apesar de programas como o PISA afirmarem avaliar a capacidade de os estudantes utilizarem conhecimentos e habilidades, adquiridos em sua escolarização, para resolver problemas cotidianos, é desconsiderado que esses conhecimentos e habilidades têm vínculos socioculturais contextuais, tornando problemática a ideia de uma avaliação internacional (Díaz Barriga, 2011; Popkewitz, 2013). Em outras palavras, o movimento por uma base nacional comum reforça as avaliações centralizadas, pretende ser o guia dessas avaliações e projeta a possibilidade de medir e comparar resultados de testes como se eles pudessem ser expressões de conhecimentos. 


\section{Conclusões - por um currículo sem fundamentos}

Para finalizar, penso ser interessante considerar a produtividade de que a política de currículo, ao invés de incorporar tantos mecanismos centralizados de tentativa de controle da significação, incorpore a dimensão do fracasso da leitura de qualquer texto político. Ao invés do esforço na fixação de bases e conteúdos curriculares comuns em nível nacional e nas ações que garantem essa fixação, assumir que diferentes negociações de sentidos produzem traduções no/do currículo. Debater contextualmente o que está sendo realizado nas escolas e o que estamos valorizando pode ser uma aposta mais produtiva para as políticas de currículo. Disseminar diferentes propostas curriculares - disciplinares, interdisciplinares ou mesmo antidisciplinares -, mobilizar diferentes caminhos e diferentes possibilidades curriculares - muitas delas estão sendo realizadas nas escolas -, promover o debate crítico sobre o que é realizado pode ser uma aposta mais plural e heterogênea.

Essa aposta, por sua vez, não é o delírio, não é conceber o mundo como significado por cada particular de forma isolada, desarticulada, sem nenhuma conexão mútua, nenhum sentido partilhado. Não é a filosofia de que os jogos de linguagem nos levam ao "Assim é se lhe parece"4 na significação. No jogo (de linguagem) que significa o currículo de uma dada maneira, de várias possíveis maneiras, há práticas discursivas que constituem formas de significar: disciplinas, tendências pedagógicas, visões de mundo, de conhecimento, de ciência, diferentes processos sociais que constituem significações e registros que possibilitam as identificações comuns, as equivalências de sentidos. No momento, por exemplo, existem práticas que nos aproximam: avaliações, formação de professores, livros, didáticos ou não, meios de comunicação, frequentemente nomeados por referência às tradições curriculares.

Tais tradições curriculares balizam a compreensão do mundo, são decorrentes de atos de poder que freiam a significação e o livre fluxo do sentido. A diferença de conceber tais tradições como discursivas está na afirmativa da instabilidade das tradições. Tradições não são regras racionais ou sedimentações históricas estabilizadas capazes de definir de uma vez por todas as possibilidades de conhecimento. São registros sujeitos às lutas políticas que instituem a significação. Tradições constantemente recriadas, traduzidas de diferentes formas.

Tentar ampliar as muitas definições curriculares e sistemas de avaliação já existentes, com seus documentos de subsídios e mais documentos de diferentes

4. Faço referência ao título da peça de Pirandello na qual é desenvolvido um jogo em que os personagens alternam interpretações igualmente possíveis para o mesmo fato, sem uma decisão por nenhuma delas. 
projetos, em direção a uma base comum nacional lque, por sua vez, pode vir a ser lida, e almejada, como uma lista de conteúdos e de padrões mínimos), em nome de uma suposta garantia da qualidade da educação, é mais uma vez desconsiderar possibilidades de reinterpretação/ ressignificação/tradução do currículo.

Esse processo é ainda mais perverso quando a qualidade da educação é vinculada à possibilidade de fornecer garantias aos empregadores de que os alunos têm as competências esperadas, tornando o processo educacional submetido fortemente às expectativas de aprendizagem vinculadas aos critérios econômicos. Todavia, mesmo que essas propostas fossem feitas - e muitas vezes o são - em nome dos projetos de emancipação e de formação crítica dos sujeitos, mesmo que estejam alinhadas com propósitos que tentam frear a colonização das escolas por discursos do mercado, do individualismo, da competitividade, do cientificismo, sua conexão com a ideia de homogeneidade e de unidade mostra-se problemática para uma perspectiva democrática. E, por vezes, viabiliza a articulação com os grupos sociais que limitam a educação a processos de mercado.

Como discuto em outro texto (Lopes, 2014), há em curso uma articulação de discursos críticos e discursos instrumentais e pragmáticos em nome do mesmo projeto de avaliar e assim garantir o conhecimento e as competências supostas como universais para todos, de maneira a garantir o que se pretende para a qualidade da educação. Trata-se de uma articulação entre perspectivas instrumentais/técnicas voltadas para o planejamento que garante eficiência social e as perspectivas críticas que apostam em um currículo político com o propósito de distribuir conhecimentos, de maneira a garantir um determinado projeto social e se antagonizar a falta de conhecimento dos estudantes. Essa falta de conhecimento tanto é significada como ameaça ao desenvolvimento do País e sua inserção em um projeto global, quanto ameaça à cidadania.

A manutenção de um projeto fixado como o melhor para todos, um conhecimento ou uma cultura comum, universalizados de uma vez por todas como melhor para todos, pode igualmente justificar toda e qualquer intervenção política, mesmos as autoritárias, em detrimento da heterogeneidade e da negociação contextual capaz de criar a significação de currículo para múltiplos projetos possíveis.

Destaco que conceber um currículo sem fundamentos é admitir a política em um cenário de incertezas e sem respostas definitivas. A ausência de fundamentos é o que nos permite estar sempre atuando politicamente na tentativa de produzir esse fundamento, sabendo-o precário. É buscar dissolver a possibilidade de uma intervenção pré-programada e com projeto de pretensão universalizante, a despeito do jogo político.

A meu ver, isso significa abandonar a política concebida como projeto de intervenção, direcionado a uma meta suposta como comum a todos os contextos, 
que tenta apagar os antagonismos e conflitos, apagando as marcas de sua contingência. Não elimina, no entanto, a ação política como luta pela significação de diferentes projetos contextuais. Tais projetos não são iguais, não remetem aos mesmos propósitos e interesses, não são neutros e tampouco servem a todos todo o tempo. Em diferentes tempos e espaços de produção de textos e discursos curriculares, a luta entre esses diferentes projetos se desenvolve Inem somos todos pela mesma educação, nem existe, ou deve existir, a mesma educação para todos). Mesmo porque discursos também podem interromper e desconstruir instituições e traduções, produzindo novos modos políticos de interpretar e agir.

Se a política de currículo deixa de ser o investimento na meta por uma base comum, isso não significa abandonar um projeto de qualidade do currículo. Significa assumir que há conflitos e antagonismos no social em torno do que se entende por qualidade, currículo, conhecimento. Por isso costumo repetir que conviver com a incerteza do jogo político parece ser o que nos resta. No processo político (como política de significação), vamos disputar o que vem a ser um currículo de qualidade.

Defender um currículo sem fundamentos remete à defesa de que não há princípios e regras absolutos, definidos cientificamente ou por qualquer outra dada razão, fora do jogo político educacional, que nos façam supor ser possível descansar da negociação de sentidos. As regras e princípios serão sempre disputados, levando a novas regras e novos princípios, sempre modificados na contextualização radical da política de currículo.

\section{Referências}

BARRETO, Edna Abreu; LOPES, Alice Casimiro. Os contextos da política de currículo: a experiência da Escola Cabana (1997/2004). Práxis Educativa (Impresso), v. 5, pp. 139-148, 2010. Disponível em: <http://www.revistas2.uepg.br/index.php/ praxiseducativa>. Acesso em: 15 set. 2014.

BHABHA, Homi. Disseminação - o tempo, a narrativa e as margens da nação moderna. O local da cultura. Belo Horizonte: Editora da UFMH, 2001.

BRASIL. Parecer CNE/CEB No: 7/2010. Assunto: Diretrizes Curriculares Nacionais Gerais para a Educação Básica. Brasília: aprovado em 07/04/2010. Disponível em: <http://www.nepiec.com.br/lesgislacao/pceb007_10.pdf>. Acesso em: $17 \mathrm{dez}$. 2011.

BRASIL. Parecer CNE/CEB No: 05/2011. Assunto: Diretrizes Curriculares Nacionais para o Ensino Médio. Brasília: aprovado em 04/05/2011. Disponível em: <http:// portal.mec.gov.br/index.php?option=com_content\&view=article\&id=12992: diretri 
zes-para-a-educacao-basica\&catid=323:orgaos-vinculados>. Acesso em: 03 fev. 2012.

BRASIL. Resolução CNE/CEB 4/2010. Assunto: Define as Diretrizes Curriculares Nacionais Gerais para a Educação Básica. Brasília: aprovado em 14 de julho de 2010. Diário Oficial da União, Brasília, 14 de julho de 2010, Seção 1, p. 824. Disponível em: <http://portal.mec.gov.br/index.php?option=com_content\&view=a rticle\&id=14906\&ltemid=866>. Acesso em: 15 set. 2014.

BRASIL. Resolução CNE/CEB 2/2012. Assunto: Define as Diretrizes Curriculares Nacionais para o Ensino Médio. Brasília: aprovado em 31 de janeiro de 2012. Diário Oficial da União, Brasília, 31 de janeiro de 2012, Seção 1, p. 20. Disponível em: $<$ http://portal.mec.gov.br/index.php?option=com_content $\&$ view=article\&id=1741 7\&ltemid=866>. Acesso em: 15 set. 2014.

CAMILLONI, Alícia R. W. de. Estándares, evaluación y currículo. Archivos de Ciencias de la Educación (4a. época), 2009, 3(3). Disponível em: <http://www. fuentesmemoria.fahce.unlp.edu.ar/art_revistas/pr.4082/p r.4082.pdf>. Acesso em: 15 set. 2014.

CUNHA, Erika; LOPES, Alice Casimiro. Organização Curricular em Áreas do Conhecimento: o nome da Política Curricular de Ciclos em Rondonópolis-MT. Revista e-Curriculum (PUCSP), v. 1, pp. 826-846, 2013.

DERRIDA, Jacques. Carta a um amigo japonês. In: OTTONI, Paulo (Org.). Tradução: a prática da diferença. Campinas : Editora da Unicamp, 2005. pp. 21-27.

DERRIDA, Jacques. Gramatologia. São Paulo : Perspectiva, 2008.

DIAZ BARRIGA, Ángel (Coord.). La prueba PISA 2006 - un análisis de su visión sobre la ciencia. México, IISUE, 2011.

FRANGELLA, Rita; BARREIROS, Débora. As múltiplas dimensões de uma políticaprática curricular: o caso da Multieducação na cidade do Rio de Janeiro. Intermeio (UFMS), v. 13, pp. 126-141, 2007.

HOWARTH, David. Discourse. Buckingham : Open University, 2000.

LACLAU, Ernesto. New reflections on the revolution of our time. Londres: Verso, 1990.

LEAL CUEVAS, Luís. Demandas curriculares da revolução pinguina: lutando pela qualidade da educação. Rio de Janeiro, Universidade do Estado do Rio de Janeiro, (Dissertação de Mestrado), 2014.

LIMA, Maria Jacqueline Girão; LOPES, Alice Casimiro. A disciplina Educação Ambiental na política curricular da Rede Municipal de Armação dos Búzios (RJ). Revista e-Curriculum (PUCSP), v. 6, pp. 1-19, 2010. Disponível em: <http://revistas. pucsp.br/curriculum>. Acesso em: 15 set. 2014.

LOPES, Alice Casimiro. Democracia nas políticas de currículo. Cadernos de Pesquisa (Fundação Carlos Chagas. Impresso), v. 42, p. 700-715, 2012a. Disponível 
em: <www.scielo.br>. Acesso em: 15 set. 2014.

LOPES, Alice Casimiro. A qualidade da escola pública: uma questão de currículo? In: Marcus Taborda; Luciano Faria Filho; Fabiana Viana; Nelma Fonseca; Rita Lages. (Org.). A qualidade da escola pública. Belo Horizonte: Mazza Edições, v. 1, pp. 15-2, 2012b.

LOPES, Alice Casimiro. Teorias pós-críticas, política e currículo. Educação, Sociedade \& Culturas, v. 39, p. 7-23, 2013. Disponível em: <http://www.fpce.up.pt/ ciie/?q=publication/revista-educa\%C3\%A7\%C3\%A3o-sociedade-culturas/edition/ educa\%C3\%A7\%C3\%A3o-sociedade-culturas-39>. Acesso em: 15 set. 2014.

LOPES, Alice Casimiro. Ainda é possível um currículo político? In: LOPES, Alice Casimiro; Alicia de Alba. (Org.). Diálogos curriculares entre Brasil e México. Rio de Janeiro: EdUERJ, 2014. v. 1, pp. 43-62.

LOPES, Alice Casimiro; MACEDO, Elizabeth. Teorias de currículo. São Paulo: Cortez, 2011.

LOPES, Alice Casimiro; CUNHA, Erika; COSTA, Hugo Heleno. Da recontextualização à tradução: investigando políticas de currículo. Currículo sem Fronteiras, v. 13, pp. 392-410, 2013a. Disponível em: <www.curriculosemfronteiras.org>. Acesso em: 15 set. 2014.

MACEDO, ELIZABETH. Currículo e conhecimento: aproximações entre educação e ensino. Cadernos de Pesquisa (Fundação Carlos Chagas. Impresso), v. 42, pp. 716737, 2012.

MASSALI, Fábio. MEC inicia consulta a estados e municípios para base nacional curricular. Agência Brasil. 12 de outubro. 2014. Disponível em: <http:// agenciabrasil.ebc.com.br/educacao/noticia/2014-08/mec-inicia-consultaestados-e-muncipios-para-base-nacional-curricular>.Acesso em: 12 out. 2014.

MATHEUS, Danielle; LOPES, Alice Casimiro. 0 processo de significação da Política de Integração Curricular em Niterói, RJ. Pro-Posições (UNICAMP. Impresso), v. 22, pp. 173-188, 2011. Disponível em: <www.scielo.br>. Acesso em: 15 set. 2014.

MATHEUS, Danielle; LOPES, Alice Casimiro. Sentidos de qualidade na política de currículo (2003-2012). Educação e Realidade, v. 39, pp. 337/2-357, 2014. Disponível em: <www.scielo.br>. Acesso em: 15.set. 2014.

OLIVEIRA, Ozerina. Movimento Comutativo da Política de Currículo: o caso da Escola Sarã. Revista de Educação Pública (UFMT), v. 17, pp. 13-24, 2008. Disponível em: <http://periodicoscientificos.ufmt.br/ojs/index.php/educacaopublica>. Acesso em: 15 set. 2014.

POPKEWITZ, Thomas. Números em grades de inteligibilidade: dando sentido à verdade educacional. In: Maria de Lourdes Rangel Tura; Maria Manuela Alves Garcia. (Org.). Currículo, políticas e ação docente. Rio de Janeiro: Editora da Universidade do Estado do Rio de Janeiro, 2013, pp. 19-50. 
PREAL. Programa de Promoción de la Reforma Educativa en América Latina y el Caribe. El futuro está en juego - Informe de la Comisión Internacional sobre Educación, Equidad y Competitividad Económica en América Latina y el Caribe. 1998, 29 p. Disponível em: <www.preal.com.br>. Acesso em: 12 out. 2014.

PREAL. Programa de Promoción de la Reforma Educativa en América Latina y el Caribe. Saindo da Inércia: boletim da educação no Brasil. Pesquisa e elaboração do documento: Ilona Becskeházy e Paula Louzano (Fundação Lemann). 2009, 66 p. Disponível em: <www.preal.com.br>. Acesso em: 12 out. 2014.

PLANO DE GOVERNO DO CANDIDATO AÉCIO NEVES. Diretrizes gerais do Plano de governo Aécio Neves. 2014, 76 p. Disponível em: <http://divulgacand2014. tse.jus.br/divulga-cand-2014/proposta/eleicao/2014/idEleicao/143/UE/BR/ candidato/280000000085/idarquivo/229?x=1404680555000280000000085>. Acesso em: 10 ago. 2014.

PROGRAMA DE GOVERNO DA CANDIDATA DILMA ROUSSEF. Mais mudanças, mais futuro. 2014, 42 p. Disponível em: <https://www.pt.org.br/wp-content/ uploads/2014/07/Prog-de-Governo-Dilma-2014-INTERNET1.pdf>. Acesso em: 12 jul. 2014.

PROGRAMA DE GOVERNO DA CANDIDATA MARINA DA SILVA. Plano de ação para mudar o Brasil. 2014, 244 p. Disponível em: <http://marinasilva.org.br/programa/>. Acesso em: 12 jul. 2014.

ROXO, Sérgio. Projeto do MEC quer unificar currículo das escolas no país. Jornal O Globo. Rio de Janeiro, 23 de maio, 2012, Caderno Educação. Disponível em: <http://oglobo.globo.com/educacao/projeto-do-mec-quer-unificar-curriculodas-escolas-no-pais-3549446>. Acesso em: 23 maio 2012.

SISCAR, Marcos. Jacques Derrida: literatura, política, tradução. Campinas: Autores Associados, 2013.

TURA, Maria de Lourdes; PEREIRA, Talita Vidal. Políticas curriculares, sistemas de avaliação e conhecimentos escolares. In: Maria de Lourdes Rangel Tura; Maria Manuela Alves Garcia. (Org.). Currículo, políticas e ação docente. Rio de Janeiro: Editora da Universidade do Estado do Rio de Janeiro, 2013. v. 1, pp. 111-125.

WEBER, Demétrio. Na educação, presidenciáveis propõem mudar currículo das escolas. Jornal 0 Globo. Rio de Janeiro, 04 de setembro de 2014. Caderno Brasil. Disponível em: <http://oglobo.globo.com/brasil/na-educacao-presidenciaveispropoem-mudar-curriculo-das-escolas-13174182\#ixzz3CMGP2rNq>. Acesso em: 04 set. 2014. 
Recebido em abril de 2015

Aprovado em maio de 2015

Alice Casimiro Lopes é doutora em educação pela Universidade Federal do Rio de Janeiro, pesquisadora nível 1 do CNPq e Cientista do Nosso Estado/Faperj. É professora associada da Universidade do Estado do Rio de Janeiro, atuando no Programa de Pós-graduação em Educação (ProPEd). E-mail: alicecasimirolopesla gmail.com 